\title{
Assessing Information Technologies for Health. Editorial
}

\section{Kulikowski', R. Haux²}

'Department of Computer Science, Rutgers- The State University of New Jersey, New Brunswick, NJ, USA

${ }^{2}$ Institute for Medical Informatics, Technicall University of Braunschweig, Braunschweig, Germany

\section{Summary}

Objectives: To provide an editorial introduction to the 2006 IMIA Yearbook of Medical Informatics with an overview of its contents and contributors.

Methods: Abrief overview of the main theme of "Assessing Information Technology for Health Care", and an outline of the purposes, readership, contents, new format, and acknowledgment of contributions for the 2006 IMIA Yearbook.

Results: Assessing information technology (IT) in biomedicine and health care is emphasized in a number of survey and review articles. Synopses of a selection of best papers for the past 12 months are included, as are original papers on the history of medical informatics by pioneers in the field, and selected research and education programs. Information about IMIAand its consituent societies is given, as well as the authors, reviewers, and advisors to the Yearbook.

Conclusions: The 2006 IMIA Yearbook of Medical Informatics highlights as its theme one of the most significant yet difficult aspects of information technology in health: the assessment of IT as part of the complexenterprise of biomedical research and practice. It is being published in a new format with a wide range of original survey and review articles.

HauxR, KulikowskiC, editors. IMIA Yearbook of Medical Informatics 2006. Methods Inf Med 2006; 45 Suppl 1: S2-4.

\section{Keywords}

Editorial, 2006 IMIA Yearbook of Medical Informatics, IT Assessment for Health, Surveys of Biomedical Informatics, Reviews of Biomedical Informatics, History of Biomedical Informatics, IMIAand its societies
Information technology (IT) assessment is invariably a challenge. In health care, the complex, hard to control interactions between rapidly changing technologies and how they are used by medical researchers and practitioners raise unique issues in measuring and judging the impact of IT. Nevertheless, if we are to improve the quality of health care for increasingly distributed and heterogeneous populations, the assessment of the health effects of our information systems on them is critical. With the development of so many specialized technologies, assessing how and whether they are truly improving diagnostic and therapeutic techniques, as well as the organization and management of care, becomes a major undertaking, with many obstacles along the way. Safety and quality of care, how care is integrated, and how affected by new technologies Must be addressed. Most recently, biomedical research, by increasingly introducing new genomic and phenotypic end-points is also beginning to have clinical impact, and requires assessment of what is a rapidly moving target.

The analysis and integration of the wide variety of human-processed biomedical and healthcare information into electronic medical records and health information systems, and its effective interleaving with decision support software, requires considerable sophistication in design, implementation, and testing. Evaluation follows a long sequence of events which requires careful planning, coordination, and feedback of how the evolving systems work and affect the practice of health care.

As an indispensable aspect of the future of health care, assessing information technologies for health is the focus of this 2006 edition of the IMIA Yearbook of Medical Informatics. The President of IMIA, Nancy Lorenzi has written the Foreword, and, following this Editorial, the Keynote to the Yearbook is focused on the IT assessment theme, written by Jan van Bemmel, Past President of IMIA and Past Rector Magnificus of the Erasmus University of Rotterdam, The Netherlands.

\section{About the IMIA Yearbook of Medical Informatics}

The Yearbook of Medical Informatics of the International Medical Informatics Association (IMIA) is distributed through IMIA's Member and Corresponding Member Societies worldwide. Since its inception in 1992 it has been the single most important publication summarizing the activities of IMIA, and showcasing the best of medical informatics research for the previous year. Due to changing demands by its readership, and the expanded availability of original papers over the web, from 2006 the IMIA Yearbook of Medical Informatics is adopting a new format and mode of publication. This is expected to substantially broaden its availability 
to virtually all members of the IMIA family. We are introducing a wider range of original survey articles which give overviews of recent developments, as well as comprehensive introductory reviews of current topics in different fields of health and biomedical informatics. There will be a history of medical informatics section with original papers on the history of the field, and reprints of pioneering articles selected by the authors. The traditional selection of "best papers" for the year will be listed with short synopses, but the papers will no longer be re-printed.

The new IMIA Yearbook of Medical Informatics appears as a supplement of Methods of Information in Medicine, one of the official journals of IMIA. As result, all original papers will be peer reviewed, Medline indexed, and impactfactor listed. The Yearbook remains a non-profit publication of IMIA, jointly published with Schattauer Verlag.

The editors appreciate the contributions of distinguished researchers in medical informatics who have prepared eight invited surveys, five invited review papers, two history of medical informatics papers, two research and education papers, and eight synopses of best paper selections included in the disciplinary fields covered. We owe a debt of gratitude to 67 reviewers who assisted in the selection of papers from the recent refereed literature.

The present Yearbook includes papers selected from the literature for the period April 2004 to March 2005. The criteria for selection include: significance, representativeness and coverage of research in a given subfield, presented at a high level of quality. A more detailed description of these quality criteria can be downloaded from http:/ /iig.umit.at/yearbook.

The overall selection is made by the editors with the advice of the eight section managing editors from each of the specialty areas. During this selection process, the managing editors first identify medical informatics papers published during the period in question, and listed in MEDLINE. The number of papers considered is close to 20,000 , from which those with the most impact on the field are pre-select for peer-review. Each of the preselected papers (about 150 each year) is then reviewed by two external international referees, by the two editors of the Yearbook, and by the responsible managing editor, using a standardized assessment form to score and rank the papers. Based on these five reviews, about 40 to 50 of the most outstanding are then finally selected for synopsis in the Yearbook.

\section{Surveys and Reviews}

The 2006 Yearbook includes for the first time a number of broad original survey articles on the topics of: Safety and Quality of Decision Support Systems (Enrico Coiera, Johanna Westbrook and Jeremy Wyatt), The Computerized Medical Record (Monique Jaspers, Petra Knaup and Diana Schmidt), Expanding the Scope of Health Information Systems (Klaus A. Kuhn, Sebastian Wurst, Oliver J. Bott, and Dario A. Giuse), Sensor, Signal, and Image Informatics (Thomas M. Lehmann, Till Aach and Herbert Witte), Decision Support, Knowledge Representation, and Management in Medicine (Mor Peleg and Samson $\mathrm{Tu}$ ), and The Path to eHealth: Obstacles on the Way (Alejandro R. Jadad and Murray W. Enkin), and Quality Assessment of Microarray Technologies (John Quackenbush).

As usual, it also includes a number of original review articles, which focus primarily on this year's theme, such as the paper by Christian Nøhr on Evaluation of Electronic Health Record Sy- stems, by Michael Rigby on Evaluation - The Cinderella Science of ICT in Health, by Jim Cimino and Xinxin Zhu on The Practical Impact of Ontologies on Biomedical Informatics, by Dipak Kalra on Electronic Health Records Standards, and by Frank A. Sonnenberg and C. Gregory Hagerty on Computer-Interpretable Clinical Practice Guidelines.

\section{Research and Education in Medical Informatics}

The Yearbook provides an opportunity for highlighting an international selection of current education, training, and research programs in Medical Informatics. In this 2006 edition, authors from Canada and the Czech Republic summarize their educational and research approaches.

\section{History of Medical Informatics}

A set of original articles appears for the first time in 2006, with contributions by pioneering researchers in the field: Morris F. Collen on Fifty Years in Medical Informatics, and Hans E. Peterson on From Punched Cards to Computerized Patient Records: A Personal Journey.

\section{Managing Editors}

After the selection of papers to be included in the Yearbook was completed, the managing editors were asked to write Synopses reviewing the papers in the different sections. The special section on Health Technology Assessment was edited by Elske Ammenwerth of the University for Health Sciences, Medical Informatics and Technology (UMIT), that on Health and Clinical 
Management by Joachim Bergmann of Braunschweig Technical University (TU Braunschweig), that on Patient Records by Petra Knaup of Heidelberg University, that on Health Information Systems by Oliver Bott of the TU Braunschweig. The section on Sensor, Signal and Imaging Informatics by Ralf Westphal and Simon Winkelbach of the TU Braunschweig, the one on Decision Support, Knowledge Representation and Management by Birgit Brigl, of the Unviersity of Leipzig, the section on Education and Consumer Informatics by Michael Marschollek of the TU Braunschweig and on Bioinformatics by Elke Lang of Darmstadt Technical University.

\section{Information on IMIA and on its Regional Groups}

The Yearbook contains detailed information about IMIA, its Member Societies, Regional Groups, Working Groups, and Special Interest Groups. Preparation of the general pages describing IMIA activities received considerable assistance from Steven Huesing, the Executive Director. The section on IMIA Working Groups and Special Interest Groups was greatly aided by contributions from Evelyn Hovenga. For the second time a more detailed report on the activities of IMIA regions is included with the help of Regional Editors. We would like to thank Arie Hasman and Rolf Engelbrecht (for EFMI), Sedick Isaacs (for Helina), Elizabeth Di Chiara and Don Detmer (for the North American IMIA Member Societies), Yun Sik Kwak (for APAMI) and Lincoln de Assis Moura, Jr. (for IMIA LAC) for their valuable contributions. The IMIA representatives from the individual countries provided the material for their own national societies.

\section{Acknowledgements}

The editors gratefully acknowledge the contributions of the referees and guest editors. They would also like to thank the authors of the invited surveys, reviews and historic papers and the contributors to the Research and Education Section.

They are most appreciative of the considerable skill, time, and effort devoted by the Managing Editors, especially the Executive Managing Editor Elske Ammenwerth and by the Section Managing Editors, Oliver Bott, Birgit Brigl, Petra Knaup, Elke Lang, Ralf Westphal and Simon Winkelbach, Michael Marschollek, and Joachim Bergmann, with affiliations and section responsibilities indicated above. They also wish to thank the Editorial Assistant, Martina Hutter, from the Medical Faculty at the University of Heidelberg, without whose untiring efforts the Yearbook would not have been completed.

The editors also wish to thank the members of the Advisory Board for their invaluable contributions to the planning of this Yearbook. They are: Marion Ball, IBM Center for Healthcare Management, Baltimore, MD, USA, Jan H. van Bemmel, Erasmus University Rotterdam, The Netherlands, and Alexa McCray, Harvard Medical School, Boston, USA.

The referees who contributed to the selection of articles in the 2006 Yearbook of Medical Informatics were:

Jos Aarts, The Netherlands

Ameen Abu-Hanna, The Netherlands

Hans Åhlfeldt, Sweden

Lincoln de Assis Moura, Jr., Brazil

Samy A. Azer, Australia

Emma-Jane Berridge, United Kingdom

Cynthia Brandt, USA

Matthieu Chabanas, France

Yuen Ho Chow, Singapore

Christopher Chute, USA

Jean-Louis Coatrieux, France

Lincoln de Assis Moura, Brazil
Etienne de Clercq, Belgium

John T. Donnelly, USA

Jens Dørup, Denmark

Georg Duftschmid, Austria

Martin Dugas, Germany

Gerald Fischer, Austria

Alejandro Frangi, Spain

Martin Frické, USA

Sergio Furuie, Brazil

Dragan Gamberger, Croatia

Sebastian Garde, Australia

Reda R. Gharieb, Egypt

Stefan Gräber, Germany

Robert A Greenes, USA

Ghassan Hamarneh, Canada

Heinz Handels, Germany

Petr Hanzlicek, Czch Republic

Dimitar Hristovski, Slovenia

Carola Hullin, Australia

Jeongeun Kim, Republic of Korea

Issac Kohane, USA

Mikko Korpela, Finland

Peter Langkafel, Germany

Beatriz de Faria Leao, Brazil

Andy H. Lee, Australia

Richard Lenz, Germany

Tze-Yun Leong, Singapore

Anne MacFarlane, Ireland

Nicos Maglaveras, Greece

Victor Maojo, Spain

Fernando Martin-Sánchez, Spain

Peter Moorman, The Netherlands

Georgina Moulton, United Kingdom

Jeannette Murphy, United Kingdom

Peter Murray, United Kingdom

Fabiane Nardon, Brazil

Christian Ohmann, Germany

Silvana Quaglini, Italy

Matthias Reuter, Germany

Batami Sadan, Israel

Richard E. Scott, Canada

Amnon Shabo, Israel

Vitali Sintchenko, Australia

Won Jay Song, Republic of Korea

Selma Supek, Croatia

Hiroshi Tanaka, Japan

Manolis Tsiknakis, Greece

Wim van Drongelen, USA

Mark van Gils, Finland

Max Viergever, The Netherlands

Johanna Westbrook, Australia

Ulrike Wittig, Germany

Ulrich Woermann, Switzerland

Shuenn-Tsong Young, Taiwan

Leong Tze Yun, Singapore 